Vol.7, No 1. Diciembre de 2015 pp. $112-133$

Artículo Original

Recibido para publicación: 1 julio de 2015. Aceptado para publicación: 20 Octubre de 2015

\title{
POLÍTICAS PÚBLICAS SOBRE INCLUSIÓN SOCIAL DE PERSONAS MAYORES EN SITUACIÓN DE CALLE
}

\section{Public policy on social inclusion of the elderly living in street}

\author{
Autores: Luz Ángela Turizo Pereira ${ }^{1}$ \\ Correspondencia: luzangelaturizo1@hotmail.com
}

\begin{abstract}
RESUMEN
En el presente artículo de investigación se analizan las políticas públicas de inclusión social dirigidas a las personas mayores que se encuentren en situación de habitantes de calle en la ciudad de Cartagena en los últimos diez años desde la alcaldía de la ciudad de Cartagena. Indagando el nivel de eficacia que han generado en el sector social y como son en realidad manifestadas estas políticas que se están efectuando para preservar los derechos fundamentales y la fijación de éstas personas en la colectividad.
\end{abstract}

\section{Palabras Claves:}

Habitantes de la calle, inclusión social, personas mayores, políticas públicas en Cartagena.

\begin{abstract}
In this research article it's going to be analyzes those social inclusion's public politics for the seniors' homeless in the last ten years from the mayoralty. Looking the level of efficacy that had been generated at the society and how really are shown those politics that want to look for the fundamental rights and to keep this people on the society.
\end{abstract}

\section{Key words:}

Homeless, social inclusion, seniors, public politics in Cartagena.

\footnotetext{
${ }^{1}$ Estudiante Derecho e intergarnte del semillero de investigación Phronesis de la universidad de Cartagena, Bolívar. Estudios de inglés nivel B2 Centro Colombo Americano, Cartagena.
} 


\section{INTRODUCCIÓN}

La pobreza se ha implantado en la sociedad Colombiana a tal punto de no encontrar la diferencia entre sus tipos y razones de surgimiento. La situación social de los Colombianos ha variado por éste y por diversos motivos adicionales, sin embargo no es preciso descifrar una razón en concreto que conlleve a las personas a vivir en la calle.

Para nadie es un secreto que el desarrollo de la personalidad de un ser está influenciada por su medio y por las decisiones que éste toma con respecto a lo que le rodea; un núcleo familiar con falencias suele ser una de las principales razones por las cuales sus miembros se excluyen de estos círculos y tienen terminaciones fatales, una de ellas es ser habitantes de calle. A pesar de esto los vacíos sociales que se ostentan en el país presentan una suma elevada de consecuencias que también llevan a que se encuentren personas en esta condición.

Las personas mayores suelen ser de los porcentajes más bajos en situación de indigencia en las ciudades Colombianas pero su inclusión social es aún más difícil que la de los niños y adolescentes ya que gracias a su edad avanzada sus habilidades han disminuido y cada vez las labores que ellos pueden realizar son más escasas. Debido a esto los proyectos que se deben aplicar hacia estas personas son aún más complejos y tienen que ser generados, usualmente, de manera muy específica para cada persona para que de esta manera se dé un pleno cumplimiento de la tarea propuesta y de la mejora en su situación de vida.

A medida que avance la investigación se establecerá que vivir en la calle es una opción de vida que trae consigo una cantidad de problemas físicos y sicológicos 
que deben ser divisados por los planes de gobierno de los dirigentes del país. $\mathrm{Y}$ aunque la sociedad estipule que es una forma errónea de vida, se enfrenta con la realidad de que hay personas que simplemente disfrutan su estancia y su modalidad de vivir en la calle de manera que no pueden ser obligadas por ningún ente estatal para que se recluyan a un centro asistencial o que se refugien en alguno.

Por esta razón este proyecto se apoya de ésta situación para indagar sobre las políticas públicas que se han establecido durante los últimos diez años en la ciudad de Cartagena desde el Distrito para mitigar e incluir en la sociedad a estas personas que al igual que todos los demás merecen un espacio en la colectividad para poder realizarse y/o mejorar su calidad de vida. Al realizar este análisis se demuestra el interés que existe por este grupo de personas y no la denigración social en la que se encuentran actualmente, ya que a pesar de que se encuentran en todos los lugares de la ciudad, ya son ignorados porque para algunos ciudadanos estas personas, con los mismos derechos y deberes que nosotros, se volvieron sencillamente parte del paisaje.

\section{MÉTODOS.}

La presente investigación se enmarcó en tipo de investigación descriptiva exploratoria, con un método deductivo, El enfoque paradigmático que cobija el proceso es el crítico social, con un enfoque cualitativo y cuantitativo. La población estuvo conformado por habitantes de calle asentados en Cartagena. 


\section{RESULTADOS Y DISCUSIÓN.}

\section{Reflexiones Jurídico-Filosóficas Sobre Pobreza Y Desigualdad}

Adentrándonos a la temática expuesta en el proyecto y de amplia preocupación social entontáramos que Colombia siendo un país pluricultural no oculta sus amplios niveles de discriminación y de exclusión social que no son más que la proyección de problemas internos como lo son la pobreza y la desigualdad.

Tomando bases en los ideales de pobreza y desigualdad de Rousseau se identifica que estos factores han existido desde que se despertó la vanidad de por lo ajeno, el deseo y la rivalidad que trae consigo. J.J. Rousseau planteó dos tipos de desigualdad, la natural o física y la moral o política de la cual rescataremos la última ya que por medio de esta encontramos el paralelo expresado entre los privilegiados y las víctimas de los perjuicios de los seres en la sociedad; es mas especifico cuando se refiere a que las leyes se tornaron útiles solo a los que poseían y todo lo contrario a los que nada poseían. Después interpretado como las expoliaciones de los ricos enfrentadas a los latrocinios de los pobres. Siendo esto último una afirmación planteada muchísimos años atrás para nadie es un secreto que los desniveles son aberrantes al referirnos a las diversas clases sociales Colombianas e incluso a los niveles en los trabajos del país con respecto a la edad y también con respecto a la mujer. Todo esto demostrando que la desigualdad es una realidad que solamente se impregna más en nuestro ser y por consiguiente en el futuro que ha de venir para Colombia.

Ampliando la relación se encuentra el filósofo Alemán Thomas Pogge con el cual se vuelve a incluir el tema de la ley por medio de las leyes de derecho internacional como lo son los derechos humanos, los cuales influencian directamente la pobreza mundial. En su pensamiento demuestra como con la 
colaboración maximizada de los países ricos sería posible la mejora de los países pobres por medio de lo planteado en su justicia global. A pesar de que suene muy utópico, la justicia global ha generado ese ideal o creado esa chispa para que los progresistas empiecen a analizar como poder ayudar y globalizar de esta manera al mundo, ya que un mundo que se encuentre en este estado generaría multiplicidad de opciones y beneficios internos e internacionales que se verían plasmados en el campo de la economía, principalmente, pero también en el aspecto social si se pudiese llegar a una aceptación de las diferencias y adaptación a los medios en los cuales se fundamenta cada persona. De esta manera se denota de forma mas amplia como desde hace un tiempo la igualdad y la pobreza eran temas de conversación y como las ayudas han sido principal recurso para todo este escenario, sin mencionar el amplio poder de la educación expuesto por diversos pensadores alrededor de la historia.

Pero de esta manera todo lo vemos de manera muy alejada a nuestra realidad y a lo que es manifestado por nuestros gobernantes que por siempre querrán vender sus campañas con mensajes de igualdad e inclusión social, cuando la verdad es que todo esto está muy alejado de la sociedad en la que vivimos, comenzando con que no quieren aceptar el problema tan grande que trae consigo una persona en situación de calle y todo lo que podrían aportar si fueran acogidos de manera mas permanente e integradora en la sociedad.

De esta manera al corresponderlos dos concepto de sociedad planteados por Rousseau y Pogge se encuentra el engranaje necesario para plantear que la indigencia es un problema del hoy que no va a cesar nunca si no se toman las medidas necesarias para crear igualdad y por consiguiente inclusión. 


\section{Marco Legal De Los Habitantes De La Calle En Colombia}

Aquí citaremos los diferentes artículos de la Declaración Universal de los Derechos Humanos, la Constitución Política Colombiana que podrían de un modo $u$ otro defender los derechos que están siendo vulnerados en el plano social, en el caso de los procesos de protección social (alimentación, salud y vivienda), igualdad institucional (trabajo y protección por parte de las autoridades) y el acondicionamiento para la inclusión social de cada individuo, decidimos hablar un poco sobre los derechos que tienen estos individuos y que el estado debe proteger.

\section{Declaración Universal De Los Derechos Humanos}

\section{Artículo 3 (comentarios de autor)}

Este artículo entra por la razón que actualmente no hay planes de desarrollo para la inclusión social de los habitantes de la calle hablando específicamente de los adultos de tercera edad, como no hay un apoyo por parte del gobierno para incluir a estos individuos a la sociedad se les estaría violando el derecho fundamental a la seguridad social ya que no tienen la alimentación adecuada, salud o vivienda.

\section{Constitución Política De Colombia}

\section{Artículo 13. (comentarios de autor)}

El Estado no está promoviendo las condiciones adecuadas para que estas igualdades se cumplan, ya que estos individuos marginados no tienen la 
capacidad de tener una vivienda digna, o el derecho a un trabajo digno, esto se ve claramente cuando tu miras a estos individuos en las calles durmiendo en el piso y pidiendo dadivas para poder alimentarse.

\section{Artículo 25. (comentarios de autor)}

Es cierto, el trabajo digno es un derecho que deberían tener todos los ciudadanos pero como ya mencionamos anteriormente no se cumple por cuestiones de discriminación, por falta de documentación o debido a la presentación de estas personas, y esta es una de las principales maneras con las que se puede incluir a estas personas en una sociedad reitero con un trabajo digno

\section{Artículo 38. (comentarios de autor)}

Se garantiza pero no se efectúa en un plano de eficacia ya que por lo general estás personas son rechazadas o discriminadas para el acceso de las distintas actividades en la sociedad.

\section{Artículo 48. (comentarios de autor)}

En el caso de este artículo demuestra el derecho irrenunciable a la seguridad social, pero en algunos casos los mismos habitantes de las calles son los que no quieren recibir este beneficio, por esa el gobierno debería tomar las medidas necesarias para que estas personas accedan a recibir este derecho y no solo dejarlos a su suerte por mero capricho.

\section{Artículo 51. (comentarios de autor)}

Bueno como ya fue mencionado en anteriores comentarios, estos individuos no tienen vivienda digna entonces se les está violando un derecho, se debe promover 
planes de vivienda interés social como se plantea en este articulo si se planea poder llegar a una inclusión social.

\section{LEYES}

\section{Ley 1251 de 2008. (comentarios de autor)}

\section{Articulo $1^{\circ}$.}

Se ha indagado acerca de los proyectos que ha tenido la administración del actual alcalde, Dionisio Vélez, incluyendo a las anteriores administraciones, la de Judith Pinedo y Campo Elias. En estos diez (10) años, se han dado varios proyectos, pero estos proyectos que fueron hechos por casetas de las organizaciones privadas que quieren la reintegración de estas personas que se alejaron del seno familiar por decisiones erróneas que tomaron a medida que su vida pasaba y sus familiares le dieron la espalda por distintas razones, y ya llevan un gran tiempo y esto los conllevo a tener este estilo de vida.

Nuestra opinión como grupo con respecto a este tema que lleva ya muchísimo tiempo a lo que se le debe prestarle muchísima atención, porque es una problemática que está en toda la ciudad y en casi todas las ciudades del país y con la creaciones de estos proyectos que buscan ayudarlos, son unos muy interesantes para que estas personas ya con edades avanzadas puedan ser acogidos por un seno familiar que los quiera y les den apoyo que necesario para salir y poder regresar a una vida más digna. 


\section{Ley 1276 de 2009. (comentarios de autor)}

\section{Artículo $1^{\circ}$.}

Pensamientos claros aquí en esta ley, que busca amparar a estas personas de escasos recursos a través de centros que buscan una reintegración y darle una calidad de vida mejor a estas personas que lo quizás lo único que tienen es lo necesario para poder sobrevivir y quizá no sea suficiente. Pensamos que es una ley muy interesante por poseer un contenido que abarca a una población que son, como se dice vulgarmente "son niños muy grandes", y busca protegerlos al no tener unos recursos para poder costearse ellos mismos, y cubrir todo lo necesario para que puedan tener una buena salud y una buena compañía en estas edades, que es muy importante para ellos en su parte afectiva saber que tienen a alguien con quien puedan pasar este tiempo

\section{Ley 1315 de 2009. (comentarios de autor)}

\section{Artículo $1^{\circ}$ y $2^{\circ}$}

Si se debe prestar atención a los servicios integrales de los adultos mayores, entonces porque los adultos mayores que cayeron en indigencia no tienen el acceso a instituciones de hospedaje, cuidado, bienestar y asistencia social de calidad porque si tienen el acceso a unos lugares llamadas casas de paso donde se ofrece algunos servicios, pero es como si llegaran recibieran los servicion y los volvieran a dejar a su suerte en la calle algo totalmente inaceptable para la concepción humanista del siglo XXI. 


\section{Ley 1171 de 2007 (comentarios de autor)}

\section{Artículos 1 y 2}

Nuestra opinión en esta ley es que se deberían instaurar una documentación para que estos individuos puedas acceder a los diferentes beneficios que esta ley consagra, pues es necesario que todas las personas podamos tener la misma accesibilidad a estos derechos.

Actualmente en Cartagena no hay políticas que intenten aumentar los índices de inclusión social por parte de los habitantes de la calle y más en específico a los adultos de tercera edad, pero hay una cierta ley que defiende la seguridad social por parte de la secretaria social de desarrollo la cual es:

A pesar de calidad de generalidad que caracteriza a estas normas antes mencionadas también tenemos que incluir el escalafón de alcaldes que rigieron en nuestro marco temporal de diez años y los principales ideales sobre este tema que los caracterizaron (a los que no se les enmarca ninguna política es porque no fue encontrada):

- Alberto Barboza Senior (1 de Enero de 2004 - 7 de Diciembre de 2005).

- $\quad$ Nicolás Curi Vergara (8 de Diciembre de 2005 - 31 de Diciembre de 2007) Fue alcalde por $\quad 3$ periodos. Conocido por el populas "reparcheo" y por esta razón la Fiscalía violó la ley 80 de contratación pública ya que debía convocar la licitación en público.

- $\quad$ Judith Pinedo Flórez (1 de Enero de 2008 - 31 de Diciembre de 2011) propuso el proyecto de gobierno con el nombre de "Por una sola Cartagena" el cual es mencionado en el artículo.

- Campo Elías Terán Dix (1 de Enero de 2012 - 14 de Noviembre de 2012). 
- Carlos Otero Gerdts (14 de Noviembre de 2012 - 21 de Julio de 2013).

- $\quad$ Dionisio Velez Trujillo ( 22 de Julio de 2013 - Actualidad)

No tiene ninguna política pública pero da apoyo a los proyectos presentados por las diversas secretarías y fundaciones.

\section{Habitantes De La Calle En La Ciudad De Cartagena}

Habitantes de la calle o personas en situación de calle, las vemos a diario devastados o deambulando por las avenidas y diversos lugares de la ciudad, personas que les han generado ciertos problemas a los administradores de la Alcaldía Mayor de la ciudad desde siempre. En los últimos diez años, los habitantes de la calle son personas del común que por razones del destino y/o malas decisiones que han tomado fueron arrastrados a una vida en las calles. No obstante, al no ser esta una de las mayores exigencias del pueblo hacia el Distrito, no es considerada como una de las principales problemáticas de la ciudad. Problemas como la educación, el desempleo, la seguridad y la pobreza extrema son los focos principales de las políticas de Cartagena, pero si se miran mas a fondo cada uno se encontrará que uno de ellos es uno de los principales causantes de los demás. La pobreza generada por factores como el desempleo adecuan a la sociedad a que disminuyan los niveles de educación, de esta manera el crimen organizado se fundamenta y la seguridad disminuye hasta sus niveles actuales. Sin embargo este análisis apresurado es solo para demostrar la incidencia de la pobreza en la ciudad y como también ésta tiene muchos frentes de donde estudiarla, uno de sus protagonistas se da por medio de la indigencia, principal forma de presentación en la actualidad, no solo porque no exista espacio para vivir dentro de la ciudad o el sinnúmero de inmigraciones que se hacen todos los días sino por disfunciones familiares que se generan y traen como consecuencia todas estas formas antes mencionadas. Tienen lugares estipulados para situarse, alimentarse, convivir y realizar sus labores diarios que no son de 
agrado para la ciudadanía pero al contrario de la mentalidad egoísta, simplemente no existe un lugar en específico para ellos.

Al realizar esta investigación, nos dirigimos hacia los entes que hacen control sobre esta población y se encontró que la Alcaldía Mayor de Cartagena de Indias, Secretaria de Participación y Desarrollo Social y la Corporación para El Desarrollo del Ser y la Comunidad MAYAELOrealizaron un estudio descriptivo de las personas mayores en situación de calle en los años 2009 y 2010, el cual arrojó los siguientes resultados:

"Contrario a lo que regularmente se piensa, la mayor parte dela población adulta habitante de calle manifiesta ser de la ciudad de Cartagena, constituyendo un $51 \%$ del total de personas contactadas. Un $25 \%$ refiere proceder de municipios y ciudades de la costa atlántica, argumentan su desplazamiento, debido a los problemas de orden público y falta de oportunidades laborales. Otro argumento encontrado para migrar de su ciudad de origen es la presión social que ejercen comunidades pequeñas señalando y censurando fuertemente el consumo de sustancias psicoactivas, situación que los hace buscar un sitio apartado de su familia donde nadie cuestione su problemática de adicción. El 24\% restante de personas encuestadas provienen de diversos puntos geográficos del país entre ellos ciudades como Medellín, Bogotá, Cali y Bucaramanga, entre otras, este porcentaje de la población llega a Cartagena en busca de oportunidades laborales, y otro pequeño grupo llega a la ciudad huyendo de peligros asociados a situaciones de violencia social y política. Es importante resaltar que un 1\% de la población de calle encuestada afirma proceder de otros países como Venezuela, panamá y Perú, y manifiestan tener más de 5 años en el país, y no contar con alguna red de apoyo en la ciudad." 


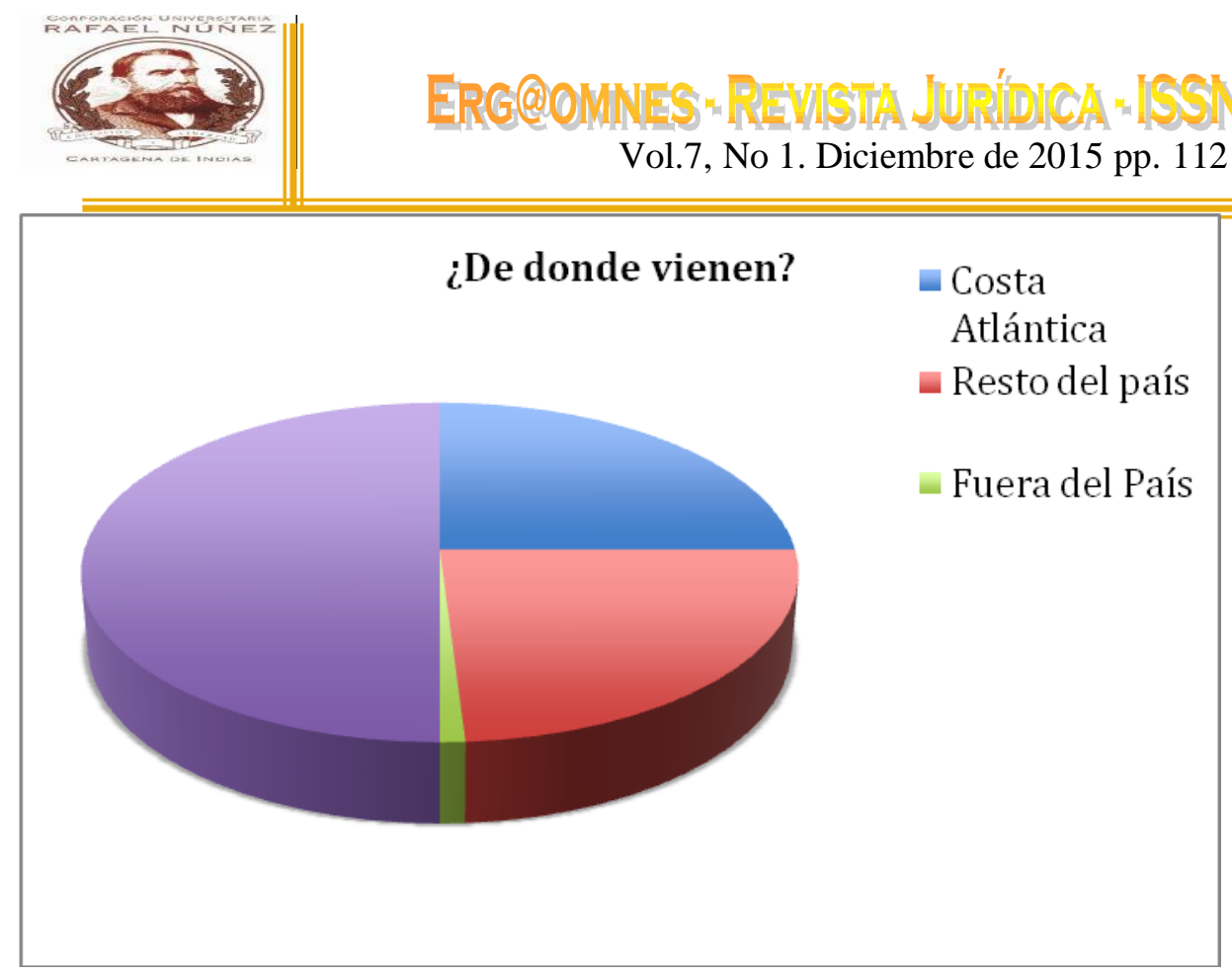

Fuente: secretaria de participación y desarrollo, Distrito Cartagena. . (2011)

Con respecto al factor de las edades nos enfrentamos con la realidad más impactante de este estudio:

"34\% de las personas encuestadas se encuentra en edades comprendidas entre los 18 y 27 años de edad, siendo adultos jóvenes, en edad productiva y reproductiva con vida sexual activa y regularmente con pareja en esta misma situación. Un $43 \%$ se encuentra en la segunda etapa de la adultez con edades entre los 28 y los 45 años, generalmente son padres de familia con varios hogares disueltos, con contacto mínimo con su núcleo familiar. Un 17\% restante está en la adultez tardía en un rango de edad de los 45 a los 60 años, estas personas llevan la mayor parte de su vida en las calles y no tienen contacto con su núcleo de origen; toda esta población constituye el $94 \%$ del total de personas encuestadas están dotados en edad productiva capaces de generar ingresos y de ser auto sostenible. Por otro lado un $4 \%$ de las personas encuestadas son adultos mayores de 60 años, quienes en su mayoría tienen problemas de consumo de alcohol y no cuentan con redes de apoyo familiar ni social; cabe resaltar que por su deterioro físico es ésta población la que más demanda atención tanto de los servicios de 
Vol.7, No 1. Diciembre de 2015 pp. $112-133$

salud, como alojamiento y alimentación, debido a que se les dificulta la obtención de recursos para sostenerse y expresan estar cansados de vivir en la calle."

Todas estas estadísticas son tomadas de la secretaria de participación y desarrollo, del Distrito de Cartagena. Año 2011.

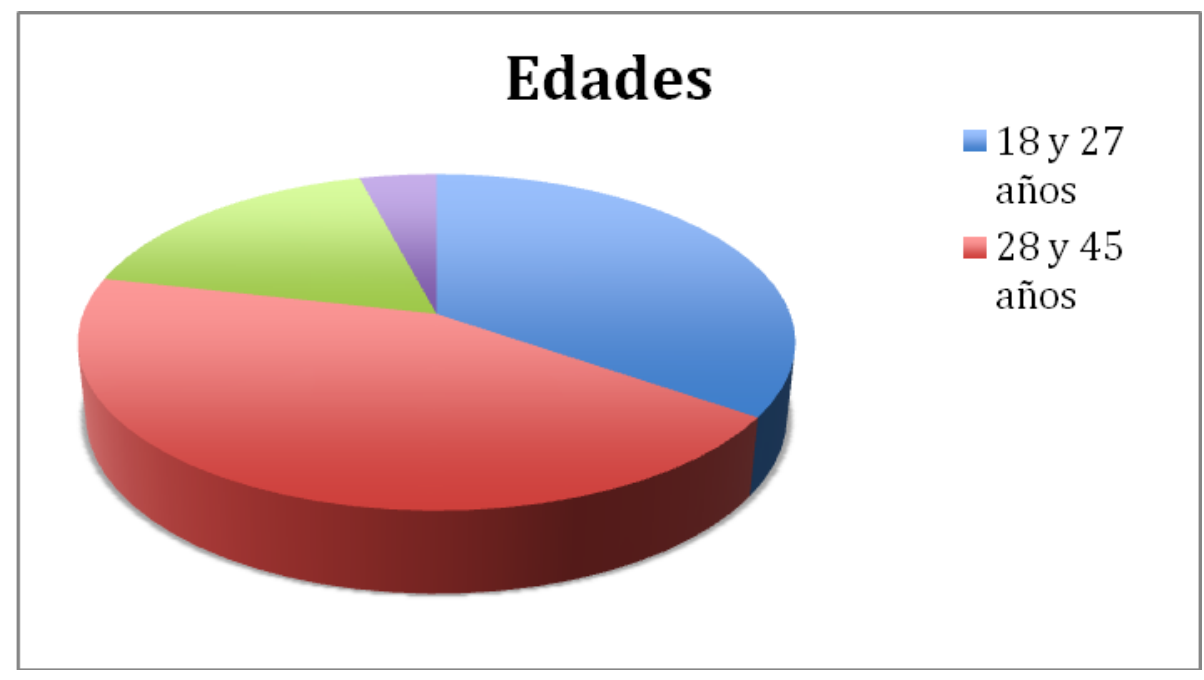

Fuente: secretaria de participación y desarrollo, Distrito Cartagena. (2011)

De esta manera se encontraron las diversas cifras que enmarcan la procedencia de las diversas ciudades del país e incluso de otros países en busca de una mejor calidad de vida o simplemente oportunidades para su realización, también la escala de edades en las cuales oscilan estas personas y los diversos oficios en los que se desarrollan. Atendiendo a nuestras pretensiones anteriores encontramos como ya se mencionó en el estudio a unos porcentajes menores de personas mayores que de niños, adolescentes, jóvenes adultos e incluso adultos. Dificultando su atención y denotando la gran cantidad de problemas a los que son víctimas por no poseer las mismas capacidades de realizar un trabajo que un joven o un adulto, incluso. Esto debería ser foco de alerta para las autoridades para que se les atendiera esas diversas falencias que poseen en su calidad de vida. Sin embargo las razones por las cuales estas personas se encuentran en ésta situación genera un rechazo por parte de las autoridades ya que el consumo 
de sustancias alucinógenas alerta de inmediato a las autoridades para que su trato hacia estas personas no sea como iguales sino como criminales.

Al ser considerados como delincuentes se le es más complicado la reintegración a la sociedad común, ya que se extiende ésta manera de ver hacia el resto de la sociedad. Por consiguiente a esto, los habitantes de la calle son considerados como principales generadores de violencia e inseguridad en la ciudad, y puede que muchos de ellos utilicen estos mecanismos para camuflarse y delinquir por este medio, pero no es la realidad total de estas personas que a veces, sencillamente no tienen un lugar para vivir.

A pesar de esta estigmatización que es generada por los órganos de control y luego naturalmente por la sociedad, se encuentran formas de integración organizadas por la Secretaría de Participación Ciudadana en forma de proyectos apoyados por la Alcaldía Mayor de Cartagena que ayudan a que se de una inclusión a estas personas por medio de servicios de salud, alimentación, entre otros. Paralelamente se les ofrece limpieza y descanso por medio de hogares de paso que no generan ninguna violación a sus derechos de transitar libremente por el país pero si cuida y preserva un poco más la salud de estos beneficiados.

\section{Análisis De Los Proyectos De La Secretaría De Participación Ciudadana}

La población de habitantes en situación de calle en Cartagena, actualmente es muy variable, podemos decir que es alrededor de más de mil personas, situadas en distintos sectores de la ciudad, uno de los más evidentes es el barrio Pie de la Popa, El Mercado, y a los alrededores del barrio San Pedro, situado cerca del centro comercial Sao, e inclusive en nuestro centro histórico se observa como los habitantes de la calle, duermen ya sea en pequeños muros u pequeñas 
madrigueras que construyen con cartón. Los habitantes de la calle luchan por sobrevivir día a día, algunos se dedican a pedir limosnas, otros simplemente se encuentran dormidos la mayor parte del tiempo, pero si bien es cierto, esta cifra es indudablemente variable, según datos obtenidos directamente de la Secretaria de Participación Ciudadana, (situada en el Centro Comercial Ronda Real, octavo piso) hace unas semanas para las fiestas del 11 de noviembre de Cartagena, se observó un incremento en la población de estos habitantes, la razón que nos dio la Secretaría es que, en épocas especialmente de fiestas, se incrementa la población extranjera que llega a Cartagena por motivo de sus festividades y hace que indudablemente crezca el porcentaje recogido anteriormente.

Las anteriores cifras fueron reveladas durante un debate sobre esta población en el Concejo. Esto sin la presencia de la Personería Distrital, el Bienestar Familiar, la Policía y la Defensoría del Pueblo, se llevó a cabo la discusión. Lo cual fue un poco desconcertante ya que como lo expone el Concejal Germán Zapata del Partido de ASI, "Iamento que estas entidades no acudieran a dicha citación y que no hayan enviado un informe sobre la problemática, debido a que a través de estas, sería posible una mejoría a las condiciones de esta población".

"Si estos organismos no actúan responsablemente con sus funciones, si no asignamos recursos suficientes para una atención integral de acuerdo a las dificultades de cada ciudadano en situación de calle, si no acabamos con las caletas del vicio que facilitan e incentivan el consumo de drogas y la dependencia de la misma y si no actuamos humanamente, no es posible que haya avances", dijo Zapata.

"Es que indudablemente el problema de los habitantes de la calle que se observa gira en torno a muchos factores, y es por esta razón que se hace difícil poder implementar una política, es un problema que va más allá, un problema abstracto, y la importancia de que cada persona y especialmente dichos organismos 
anteriormente, quieran y sientan el deber de colaborar para la comunidad, especialmente para los habitantes de la calle" de esta manera nos expresa la secretaría de participación.

Por parte del Distrito acudió la secretaria de Participación Ciudadana, Rocío Castillo quien reveló que "el $2 \%$ de esta población son extranjeros; el $42 \%$, cartageneros, el $21 \%$ de la Costa Caribe y el $17 \%$ procede del interior del país". Sin embargo para Castillo no se puede decir que la población aumenta permanentemente sino que es flotante con cada evento nacional e internacional que se da en Cartagena, hasta donde llegan temporalmente estas personas para pedir recursos a los visitantes.

La funcionaria reveló que existen tres hogares de paso en la ciudad en los que se atienden con un equipo interdisciplinario a 60 de estas personas cada día con alimentación, ropa y camas. Estos hogares de paso son generalmente apoyados por estrategias que crea la Secretaría de Participación, en las cuales se hacen primeramente llamamientos, es decir que se investiga cuántos habitantes de la calle hay, luego, personas aptas para el trabajo, se encargan de tratarlos, acercarse a ellos, hablarles, explicarles que lo que buscan es brindarle una ayuda y poder atribuirle lo necesario para satisfacer sus necesidades, este proceso generalmente dura 2 semanas, ya que algunos habitantes simplemente rechazan la ayuda brindada por el Distrito, mientras que otros un poco indecisos son convencidos y atienden, cuando estos logran aceptar la ayuda, además de recibir dotaciones de comida y ropa, son visitados por algunas Entidades Promotoras de Salud, las cuales les hacen respectivos exámenes, como exámenes del azúcar, de sangre, entre otros tratamientos que se le obsequian. Es importante aclarar que a estos habitantes no se les presiona para que acepten dicha ayuda, muchos de ellos simplemente dicen "No me interesa, quiero seguir mi vida asi" no se les puede retener a la fuerza. 
"No los tratamos coercitivamente porque se trata del querer ser por parte de ellos, algunos se quieren quedar pero los demás llegan a las 8 de la noche y salen a las seis de la mañana a reciclar; por ejemplo en un hogar de paso que se abrió en Ceballos se han logrado avances, 15 de esta personas no quieren volver a la calle", dijo Castillo.

La funcionaria está de acuerdo en que los recursos, que actualmente es de 500 millones de pesos al año, debe aumentarse pero que se ha ido avanzado en esa materia. Zapata concluyó que lo que se quiere es que desde la familia se ataquen las causas como la drogadicción, haya más afecto familiar y que el Distrito amplíe su rango de atención a esta población.

Si bien es cierto, actualmente, con el alcalde Dionisio Vélez se han ido implementando proyectos para el trato y la importancia de estos, especialmente la primera dama es quien se ha interesado mucho en estos temas. No se tiene una fecha concluyente acerca de cuándo será el evento o proyecto que esta realizará, pero según dicho por su secretaria personal, se le apoyará con toda colaboración a la Secretaría de Participación.

Para que los habitantes de la calle puedan disfrutar de estos beneficios que actualmente proponen estrategias implementadas por el Distrito de Cartagena especialmente en estos tres hogares de paso se hace una lista censal la cual prioriza a los que están en peores condiciones que otros. Esto se da por organizaciones como el DADIS para que luego la Secretaria De Participación les expida un certificado de indigencia con el fin de poder pertenecer al sistema de salud subsidiado (EPS) de los cuales hacen parte 512 personas.

La razón principal por la cual estas personas se convierten en habitantes de la calle es porque generalmente sus hogares son disfuncionales lo cual los conlleva al mal uso de sustancias psicoactivas. Se le considera "habitante de calle" a 
aquellas personas que por decisión voluntaria se alejan del seno familiar por más de 30 días (para aclarar, no toda persona que se aleje del seno familiar por más de 30 días es porque decida ser habitante de calle voluntariamente, hay casos en los que se ve forzada el desplazamiento de este de su seno familiar Ej.: desplazamiento forzado).

La secretaría de Participación manifestó que además de tener problemas en la familia, las sustancias psicoactivas como la marihuana, la cocaína, pero más que todo el llamado "perico", generan un aumento evidente en el índice de habitantes de calle. A pesar de esto hay habitantes de calle que reflexionan y que aceptan la ayuda brindada por el Distrito y cuentan con la posibilidad de reformarse e integrarse a la sociedad por medio de la búsqueda de trabajo por medio del cual se pueda ganar un sueldo que permita mantener el mínimo vital. En especial se encuentran las personas adultas que aceptan la ayuda brindada por el Estado porque no quieren vivir más en esas condiciones y esto dignifica la labor que se está realizando desde estos proyectos.

Estos hogares de pasos luchan por la reivindicación de los Derechos fundamentales de estas personas. Como tal en Cartagena no hay políticas públicas que regulen la indigencia, hay estrategias implementadas por la Secretaría de Participación. En Colombia solo Bogotá y Medellín tienen Políticas Públicas que regulan o tratan de controlar y disminuir los niveles de habitantes de la calle y logran un gran avance en su inclusión social, en Cartagena se plantea la necesidad de crear una política pública acerca de este tema pero la Secretaría de Participación alega que la realización de estas políticas públicas es muy arduo, ya que para que se de la ejecución o creación de estas se necesita que participen los distintos sectores de la ciudad y de esta manera generar una inclusión holística.

Para implementarlas se necesita hacer una mesa de trabajo con todos entes de los sectores de la ciudad, aunque no es tan fácil ya que es muy transversal y hay 
que articular toda la intervención. Las personas que se hacen cargo de ellos les brindan asistencia psicosocial, cabe destacar que a ellos no se les priva de su libertad, pueden entrar y salir de estos lugares por voluntad propia. Actualmente confiamos en que se pueda llegar a esa idónea y anhelada política pública, que pueda contribuir de manera positiva en los índices de porcentaje de los habitantes de la calle.

\section{CONCLUSIONES}

Para iniciar con la conclusión de nuestro artículo, es pertinente comenzar con la idea concisa de políticas públicas, y es que debemos entender que las políticas públicas son aquellas acciones de gobierno que buscan cómo dar respuestas a las diversas demandas de la sociedad, se pueden entender como uso estratégico de recursos para aliviar los problemas nacionales o como se trata en nuestro artículo de un problema especialmente local.

Generalmente las Políticas Públicas tienen que ver con el acceso de las personas a bienes y servicios. Consisten, precisamente, de reglas y acciones que tienen como objetivo resolver y dar respuestas a la multiplicidad de necesidades, intereses y preferencias de grupos y personas que integran una sociedad. Estas políticas tienen como objetivo principal buscar una solución oportuna y eficaz contra situaciones o problemas sociales. Actualmente en Cartagena, como hemos mencionado o respondido anteriormente, no se ha logrado llevar a cabo una política pública que logre integrar de manera eficiente a los habitantes de la calle, y especialmente a los hombres de edad, que notoriamente viven en condiciones precarias, pero el problema además de la falta o ausencia de políticas públicas, radica en la familia, hemos encontrado que los hombres de edad, ya no cuentan con ayuda por parte de su familia, y esta es una razón por la cual aumenta notoriamente el índice de indigencia en Cartagena. Al ser una ciudad turística es llamativa para los habitantes, y además de esto los familiares de estos se 
comportan completamente ajenos a su situación. La Corte Constitucional ya se ha pronunciado de tal manera que exige que las familias del afectado por esta situación respondan por estas personas. Sin embargo los nucleos familiares llamados a socorrer a uno de sus miembros usualmente no cuentan con los recursos para lograrlo.

Por medio de la sentencia T696/12, con ponencia en la magistrada María Victoria Calle como respuesta a una acción de tutela, decide que el mínimo vital del habitante de la calle debe ser un derecho que debe prevalecer y que como familiares que son deben velar por la seguridad del habitante, y mucho más cuando cuentan con las condiciones para satisfacer sus necesidades básicas.

Ya que hemos tocado dos puntos de manera concisa, podemos concluir que el problema de los habitantes de la calle, no es un problema que se solucione de la noche a la mañana, y como es sabido, es meramente abstracto, no es tan simple como muchos piensan, actualmente poder sobrellevar los índices de pobreza ha sido todo un reto, tratar de disminuir los de indigencias es otro más, y es que de cierta forma, son dos índices que van de la mano, y que la ciudad de Cartagena, especialmente la alcaldía y la Secretaría de Participación Ciudadana están dispuesto a asumir el reto de crear una solución para así controlar este problema social, que se ha venido dando a lo largo del tiempo, por múltiples factores. 


\section{REFERENCIAS.}

Constitución Política de Colombia

Rousseau, J. (1762) - Contrato social.

Pogge, T. (2002) - La pobreza en el mundo y los derechos humanos.

Declaración Universal de Derechos Humanos

Pogge, T. (2012) - ¿Estamos violando los derechos humanos de los pobres del mundo?

Secretaria de participación y desarrollo social, Distrito de Cartagena \& Corporación para el Desarrollo del Ser y la Comunidad Mayaelo (2011) - Estudio Descriptivo de Personas Adultas en Situación de Calle en la ciudad de Cartagena De indias.

http://www.eluniversal.com.co/cartagena/nacional/abandono-de-adultos-mayoreses-delito-126645

Moreno, L. J. \& Benadivez, M. R. (2010) Caso final: indigencia en Bogotá. Universidad Francisco José de Caldas. 